\title{
Efficacy of subarachnoid block for caesarian section using hyperbaric bupivacaine with fentanyl
}

\author{
Amal Kumar Laha, Deepannita Sutradhar, Bipul Deka, Rumi Baruah \\ Correspondence: Dr Amal Kumar Laha, Associate Professor, Department of \\ Anesthesiology, FAA medical College and Hospital, Barpeta, Assam, India; Email - \\ drlaha72@gmail.com \\ Distributed under Creative Commons Attribution-Share Alike 4.0 International.
}

\begin{abstract}
Objectives: The study was undertaken to observe the effect of intrathecally administered fentanyl with bupivacaine on onset and duration of sensory and motor block, quality of anaesthesia and requirement of analgesia during early postoperative period. Method: In this study 45 women of group 1 received hyperbaric bupivacaine $10 \mathrm{mg}$ and 45 women of group 2 received bupivacaine $10 \mathrm{mg}$ with fentanyl 12.5 mg. Onset of sensory and motor block, height of block, sensory regression, requirement of analgesic and any complication were recorded. Result: The onset time for analgesia was significantly shorter in group 2 than in group1 ( $1.9 \pm 0.56$ vs $2.46 \pm 0.79)$. The mean time for sensory regression to L1 is shorter in group1 compared to group 2 . The mean time for two segments sensory regression was significantly prolonged in group2 compared to group 1. Time for complete sensory recovery when rescue analgesia was required in postoperative period was significantly prolonged in group 2 compared to group 1 (259.4 \pm 35.3 vs 165.0土23.8). There were no significant differences between the two groups with regard to incidence of nausea and vomiting, shivering and pruritus. Conclusion: Addition of fentanyl to hyperbaric bupivacaine augments sensory block without affecting motor block.
\end{abstract}

Keywords: Intrathecal, bupivacaine, fentanyl, caesarian section.

Spinal anaesthesia is commonly employed for intrathecally administered fentanyl $12.5 \mu \mathrm{gm}$ with caesarean delivery. The intrathecal injection of fentanyl is found to augment the analgesia produced by local analgesic without causing respiratory depression [1]. Intrathecal bupivacaine alone may be insufficient to provide complete relieve from visceral pain despite high sensory block. Furthermore, large doses of intrathecal bupivacaine were associated with sever hypotension and delayed recovery of motor block [2]. bupivacaine $10 \mathrm{mg}$ on onset and duration of sensory and motor block, quality of anaesthesia and requirement of analgesia during early postoperative period.

\section{Methods}

This prospective double blind randomized study included 90 patients of Anaesthesiology (ASA) grade 1 \& 2, undergoing elective caesarian section, after Our study was undertaken to study the effect of obtaining permission from ethical committee. Patients

Received: $13^{\text {th }}$ July 2016. Accepted: $10^{\text {th }}$ August 2016.

Laha AK, Sutradhar D, Deka B, Baruah R. Efficacy of subarachnoid block for caesarian section using hyperbaric bupivacaine with fentanyl. The New Indian Journal of OBGYN. 2017; 3(2): 105-7 
with acidosis, diabetes mellitus, gastro-intestinal disease, antepartum hemorrhage, severe hypertension and disorder of coagulation profile were excluded from the study. Patients were divided into two groups. An intravenous line was secured with $18 \mathrm{G}$ cannula and preloading was done with $500 \mathrm{ml}$ of Ringer Lactate over 15 minutes. Ondansetron $10 \mathrm{mg}$ and ranitidine $150 \mathrm{mg}$ were administered

\begin{tabular}{|l|l|l|l|}
\hline Table 1: Demographic parameters in the two groups \\
\hline Variables & \multicolumn{1}{|c|}{ Group 1 } & Group 2 & P value \\
\hline Age & $24.75 \pm 4.49$ & $24.10 \pm 4.43$ & 0.49 \\
\hline Weight (kg) & $62.6 \pm 2.6$ & $61.9 \pm 2.5$ & 0.196 \\
\hline Multiparas (No of women) & 28 & 24 & - \\
\hline Duration of operation (min) & $63.20 \pm 9.95$ & $62.56 \pm 7.93$ & 0.736 \\
\hline \multicolumn{4}{|c|}{$P$ value $<0.05$ Significant (Fisher's Exact Test) } \\
\hline
\end{tabular}
intravenously. Standard monitoring was applied and base line parameters were recorded. Dural puncture was done with $25 \mathrm{G}$ quincke spinal needle in left lateral position of patient on horizontal table. Patients received either $10 \mathrm{mg}$ bupivacaine or $10 \mathrm{mg}$ bupivacaine with $12.5 \mathrm{mg}$ fentanyl. Patients were turned to supine position after intrathecal injection and a wedge was kept under right gluteal region. Oxygen is administered at $31 / \mathrm{min}$ though face mask. Hypotension was treated with rapid infusion of intravenous fluid and incremental doses of mephentermine. Bradycardia, heart rate less than 60/min, was treated with $0.6 \mathrm{mg}$ atropine intravenously.

All patients were assessed for: 1) The time of onset of sensory analgesia at T10 segment by pin

\begin{tabular}{|l|l|l|l|}
\hline \multicolumn{4}{|l|}{ Table 2: Characteristics of block } \\
\hline Duration (min) & Group 1 & Group 2 & P value \\
\hline Time for onset of analgesia & $2.46 \pm 0.79$ & $1.9 \pm 0.56$ & 0.0246 \\
\hline $\begin{array}{l}\text { Time for highest level of } \\
\text { analgesia }\end{array}$ & $5.3 \pm 1.92$ & $3.9 \pm 1.63$ & 0.230 \\
\hline $\begin{array}{l}\text { Time for two segment } \\
\text { sensory regression }\end{array}$ & $99.78 \pm 17.69$ & $129.11 \pm 31.26$ & 0.0003 \\
\hline $\begin{array}{l}\text { Time for sensory regression } \\
\text { to L1 }\end{array}$ & $179.44 \pm 28.95$ & $271.44 \pm 34.72$ & 0.232 \\
\hline Duration of analgesia & $165.0 \pm 23.8$ & $259.4 \pm 35.3$ & 0.01 \\
\hline $\begin{array}{l}\text { Time of onset of grade III } \\
\text { motor block }\end{array}$ & $3.1 \pm 0.88$ & $2.6 \pm 0,8$ & 0.530 \\
\hline $\begin{array}{l}\text { Total duration of grade III } \\
\text { motor block }\end{array}$ & $119.28 \pm 20.5$ & $117 \pm 13.4$ & 0.53 \\
\hline \multicolumn{3}{|l|}{} \\
\hline
\end{tabular}
prick method, 2) The maximum level of sensory blockade achieved, 3) The time taken for sensory regression - two segment regression and regression to L1, 4) Degree of motor blockade in Bromage score, 5) Duration of effective analgesia when patient demand rescue analgesia, 6) Cardiovascular status and 6) Any complication like nausea, vomiting, shivering and pruritus.

All data were collected in structured proforma. The statistical analysis was done with the help of Graph Pad Instat 3 software.

\section{Results}

There were no statistically significant differences

variables (table 1). The onset time of sensory analgesia was rapid in group $2 \mathrm{c}$ ompared to group 1. The time for sensory regression of two segment, between the two groups with regard to demographic sensory regression to $\mathrm{L} 1$ and time for complete sensory recovery were significantly prolonged in group 2(table 2). Pruritus was found in $6.7 \%$ of patients of group 2 .

\section{Discussion}

The addition of fentanyl to bupivacaine hastens the onset time and prolong the duration of analgesia. Hunt et at observed faster onset of action on combination of fentanyl with bupivacaine [3]. The mean time of two segments regression was significantly prolonged in group 1 compared to group 2 . The total duration of 
The New Indian Journal of OBGYN. 2017 (January-June); 3(2)

\begin{tabular}{|l|l|l|l|}
\hline Table 3: Complications in Group 1 and Group 2 \\
\hline Complications & Group 1 & $\begin{array}{l}\text { Group } \\
\mathbf{2}\end{array}$ & P value \\
\hline Nausea \& Vomiting & 8 & 6 & 0.7 \\
\hline Shivering & 9 & 3 & 0.11 \\
\hline Pruritus & 0 & 3 & 0.2 \\
\hline Bradycardia & 5 & 3 & - \\
\hline \multicolumn{4}{|l|}{ P value $<0.05$ Significant (Fisher's Exact Test) } \\
\hline
\end{tabular}

Conflict of interest: None. Disclaimer: Nil.

\section{References}

1.Choi DH, Ahn HJ, Kim MH. Bupivacaine sparing effect of fentanyl in spinal anesthesia for caesarian delivery. Regional Anesthesia Pain medicine. 2000; 25: 240-5.

2.Chung CJ, Bae SH, Choeky, Chin YJ. Spinal anaesthesia with $0.25 \%$ hyperbaric bupivacaine for caesarian section, effect of volume. Br J Anaesth. 1996; 77: $145-9$

effective analgesia without rescue analgesic in the early postoperative period was significantly prolonged in group 2. The result of our study was similar to that of studies of Uma Srivastaba et al and Belzarena Sergio $[4,5]$. Duration of motor block wasn't statistically different in the groups. Uma Srivastava et al and Belzarena Sergio also observed that adding fentanyl to bupivacaine didn't prolong motor block. There were no significant differences between the two groups with regard to incidence of nausea and vomiting, and shivering. Manullang et al observed decreased incidence of emesis with intrathecal fentanyl, and concluded that reduced incidence of emesis was because of attenuating visceral pain with fentanyl [6]. As all patients of our study received intravenous ondansetron, so difference of incidence of emesis is not significant in our study. Three patients of group 2 experienced mild nasal itching that did not required any treatment .In a study, Buvanendran A et al found that intrathecal bupivacaine attenuates pruritus from intrathecal fentanyl on all parts of body except the face [7].

\section{Conclusion}

The onset time of sensory block was rapid along with prolong duration of analgesia without affecting the motor block was observed in group of patients who received bupivacaine with fentanyl.

3.Catherine OH, Stephen JN, Angela MB, Martha AH, Jasmine VV, Datta S. Perioperative analgesia with subarachnoid fentanyl-bupivacaine for cesarean delivery. Anesthesiology. 1989, 71: 535-40.

4.Srivastava U, Kumar A, Gandhi NK, Saxena S, Datta D, Chandra $\mathrm{P}$, et al. Hyperbaric or plain bupivacaine combined with fentanyl for spinal anaesthesia during caesarean delivery. Indian J Anaesthessia. 2004; 48: 44-6.

5.Belgarena S. Clinical effect of intrathecally administered fentanyl in patients undergoing cesarean section. Anesthesia Analgesia. 1992; 74: 53-7.

6.Manullang TR, Viscomi CM, Pace NL. Intrathecal fentanyl is superior to intravenous ondansetron for

perioperative nausea during cesarean delivery with spinal anesthesia. Anesth Analg. 2000; 90: 1162-6.

7.Asokumar B, Newman LM, McCarthy RJ, Pharm P, et al. Intrathecal bupivacaine reduces pruritus and prolongs duration of fentanyl analgesia during labor: A prospective randomised controlled trail. Anesth Analg. 1998; 87:

1309-15.

Amal Kumar Laha ${ }^{1}$, Deepannita Sutradhar ${ }^{2}$, Bipul Deka ${ }^{3}$, Rumi Baruah $^{4}$

${ }^{1}$ Associate Professor, Department of Anaesthesiology, FAA Medical College, Barpeta, Assam, India; ${ }^{2}$ Assistant Professor, Department of Anaesthesiology, Silchar Medical College, Silchar, Assam, India; ${ }^{3}$ Assistant Professor, Department of Anaesthesiology, FAA Medical College, Barpeta, Assam, India; ${ }^{4}$ Associate Professor, Department of Anaesthesiology, FAA Medical College, Barpeta, Assam, India 